Disponível em: https://www.batepapocomnetuno.com/post/situa\%C3\%A7\%C3\%B5es-de-ass\%C3\%A9dio-em-mulheres-embarcadas. Último acesso: 2 de novembro de 2020.

6. Chan, D. K. S.; Chow, S. T.; Lam, C. B.; Cheung. S. F. “Examining the job-related, psychological, and physical outcomes of workplace sexual harassment: a meta-analytic review". Psychology of Women Quarterly, 32(4) 2008. Disponível em: https://doi.org/10.1111/j. 1471-6402.2008.00451.x

7. Clancy, K. B. H.; Nelson, R. G.; Rutherford, J. N.; Hinde, K. "Survey of Academic Field Experiences (SAFE): trainees report harassment and assault". 2014. Disponível em: https://doi.org/10.1371/journal. pone. 0102172

8. Österblom, H.; Wabnitz, C. C. C.; Tladi, D. et al. "Towards Ocean Equity". Washington, DC: World Resources Institute. 2020. Disponível em: www.oceanpanel.org/how-distribute-benefits-ocean-equitably.

9. Belém Statement. 2017. Disponível em: https://ec.europa.eu/research/iscp/pdf/belem_statement_2017_en.pdf.

\section{A dÉcada da GIÊNGIA OGEÂNIGA PARA O DESENVOLVIMENTO SUSTENTÁVEL. E EU COM ISSO?}

Ronaldo A. Christofoletti, Andrezza J. Gozzo, Ana Carolina de A. Mazzuco, Fernando R. Martins, Paula Kasten, Tatiana M. Mazzo, Barbara L. Ignacio, Marcelo V. Kitahara, Melissa V. Rodrigues, Leonardo Q. Yokoyama, Aline C. de Sousa, Amanda V. Aguiar, Bruno H. Basso, Carolina F. Faria, Crhisângela G. R. Ferreira, Felicia C. Gasparini, Henrique Morgan, Henrique V. Dantas, Henry M. Raphael, Juliana S. Pires, Kananda M. Vieira, Ketellyn S. dos Santos, Lucas R. Ozores, Luisa F. Medeiros, Mariana C. Lazaretti, Mariane S. Guarachi, Matheus T. Mathias, Murilo F. Carvente, Sabrina C. da S. Nascimento e Stheffany de Oliveira Santos

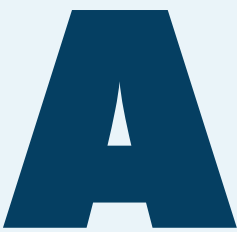

construção de um futuro sustentável passa por mudanças de comportamento de todos nós, de indivíduos a instituições. A Década da Ciência Oceânica para o Desenvolvimento Sustentável (2021-2030) [1], também conhecida por Década do Oceano, é um convite para atuarmos de forma proativa, integrada, revendo conceitos e ações, e construindo as mudanças necessárias para atingirmos o tão sonhado e necessário desenvolvimento sustentável. A oportunidade de mudança e de contribuir para esse futuro melhor e possível já começou e é um convite para participação ativa e colaborativa de toda a sociedade - independente do setor de atuação, da distância de residência do mar ou dos conhecimentos atuais sobre o oceano que cada um possui.

Como destacado no nome, a Década da Ciência Oceânica para o Desenvolvimento Sustentável possui características essenciais que formam uma chance única de transformação. A primeira é a de que esta é a Década da Ciência Oceânica, reconhecendo assim o papel central da ciência em nossa sociedade. A segunda é a de ser a ciência oceânica orientada para o desenvolvimento sustentável, ou seja, o olhar científico buscando melhoria da qualidade social, ambiental, econômica e cultural de todos de forma integrada ao longo do tempo futuro. Assim, a Década do Oceano possibilitará abordar os 17 Objetivos do Desenvolvimento Sustentável (ODS) da Agenda 2030 [2] a partir do ODS 14: vida na água. Mais do que abordar o ODS 14 em si, a Década do Oceano traz o convite para um plano de ação em que todos os ODS sejam trabalhados conjuntamente a partir da zona costeira e do oceano como exemplos de construção para um futuro sustentável.

A zona costeira apresenta uma grande diversidade de ambientes, de culturas tradicionais, de grandes cidades e atividades econômicas [3]. Consequentemente, essas áreas apresentam uma mistura de riquezas e impactos de açōes humanas. Além disso, são 
um elo de conexão, afinal, é a partir da zona costeira que as áreas terrestres se conectam ao mar e os continentes se conectam pelo oceano. Este, por sua vez, concentra a maior biodiversidade do planeta e é responsável por mais de $50 \%$ do ar que respiramos, além de ser fonte de alimentos e recursos biotecnológicos e de, dentre tantos outros serviços ecossistêmicos, ser imprescindível para a manutenção do clima, influenciando áreas rurais e produçōes agropecuárias através da regulação climática. O oceano é um universo misterioso e instigante de nossa curiosidade, com muitas preciosidades que influenciam nossas vidas em todos os momentos e que, ainda, conhecemos muito pouco [4].

A descrição geral da Década do Oceano nos mostra uma ação ampla e, eventualmente para quem não trabalha diretamente com o mar, pode parecer teórica ou distante do nosso dia a dia. Porém, é na estruturação e fundamentação desse processo que estão as oportunidades onde cada um pode fazer a diferença, mesmo que nunca tenha visto o mar. Então, a pergunta que surge é: qual o papel da Década na minha vida e como participar? Aqui, propomos uma reflexão sobre pontos chaves desse movimento: o conceito de ciência e a integração das açôes locais às metas globais. Vamos abordar esses assuntos a partir do exemplo do Brasil como país pioneiro nas ações para a Década do Oceano, com uma descrição desse processo, dos desafios, aprendizados e um olhar para o futuro.

QUE CIÊNCIA É ESSA? Muitos se questionam sobre as diferenças entre ciência oceânica, oceanografia e ciências do mar. Enquanto diferentes grupos ou autores podem indicar divergências sutis entre as áreas, o conceito geral e mais amplo defendido pela Década do Oceano apresenta uma ciência interdisciplinar:

"No contexto da Década, o oceano é considerado como parte do sistema Terrestre maior, estendendo-se da costa ao mar aberto, e da superfície do oceano ao fundo do solo oceânico. O termo "ciência oceânica" abrange disciplinas de ciências naturais e sociais, incluindo tópicos interdisciplinares; a tecnologia e infraestrutura que apoia a ciência do oceano; a aplicação da ciência oceânica para beneficio da sociedade, incluindo transferência de conhecimento e aplicações em regiōes que carecem de capacidade cientifica; e as interfaces ciência-politica e ciência-inovação. Esta definição considera as interaçōes terra-mar, oceano-atmosfera e oceano-criosfera. A ciência oceânica reconhece, respeita e incorpora os conhecimentos locais e indigenas." [1]

Desta forma, a Década da Ciência Oceânica destaca o oceano em suas dimensões ambientais, biológicas, sociais e interdisciplinares para a sociedade. A produção científica da ciência oceânica no Brasil tem crescido com importantes contribuiçōes no cenário nacional, a despeito dos desafios e limitações a serem vencidos no cenário nacional [5] e de parcerias internacionais [6]. A promoção de uma década a partir de uma visão interdisciplinar da ciência oceânica permite que a produção científica, bem como a formação de estudantes e profissionais que entrarão em breve no mercado de trabalho, sejam atualizadas a partir desse conceito, favorecendo o avanço científico e o desenvolvimento em diferentes setores da ciência que precisamos para o futuro que queremos e precisamos [7].

Além disso, uma Década da Ciência Oceânica destaca o papel central da ciência em nossa sociedade. Apesar da ciência, tecnologia e inovação serem pilares do desenvolvimento sustentável, ao longo das últimas décadas vivenciamos um distanciamento entre os saberes científicos e os demais setores da sociedade. Esse processo de distanciamento contribuiu para o momento difícil que vivemos em todo o mundo, onde há o crescimento do negacionismo científico, a propagação de fake news e a diminuição nos investimentos em ciência, tecnologia e inovação. Assim, a oportunidade de destacar e ampliar o entendimento sobre o papel da ciência e sua importância para um desenvolvimento sustentável são imprescindíveis para reverter esse cenário junto da sociedade [8]. Para isso, a Década do Oceano faz outro convite, o de olhar a ciência para além da produção científica, promovendo o conceito de ciência transformadora:

"A noção de transformação é central para a Década. A Década, tanto em termos de ação quanto de resultados, precisa ir além da forma costumeira de ações para uma verdadeira revolução na ciência oceânica. As diferentes maneiras pelas quais a natureza transformadora da Década irá se manifestar inclui a promoção e facilitação da ciência oceânica que:

- utiliza a Agenda 2030 como uma estrutura central para identificar e abordar as questôes sociais mais urgentes relacionadas com o ODS14 e ODS relacionados;

- écoprojetada c coentregue em um ambiente participativo entre múltiplos setores da sociedade para ser relevante e responsiva em toda a cadeia de valor desde a geração de conhecimento, até aplicaçôes e serviços que promovam soluçōes cientificamente embasadas;

- é focada em soluções e contribui para uma ampla variedade de potenciais soluções, incluindo política, tomada de decisão, estruturas de gestão ou governança, ou tecnologia, desenvolvimento e inovação;

- quando necessário, é grande, audaciosa, voltada para o futuro e geograficamente abrangente;

- atinge todas as disciplinas e integra ativamente as ciências naturais e sociais;

- incorpora os conhecimentos local e indígena como fontes chave de conhecimento;

- étransformadora por causa de quem a está fazendo ou do lugar onde está sendo feita, incluindo em ambos os casos países menos desenvolvidos e desenvolvidos;

- Luta pela diversidade geracional, de gênero e geográfica em todas as suas manifestaçōes; 
- é comunicada em formas que são amplamente compreendidas em sociedade e que desencadeiam entusiasmo sobre o oceano e a mudança de comportamento; $e$

- é compartilhada abertamente, ficando disponivel para reutilização." [1]

Assim, a ciência oceânica esperada para a Década, além de interdisciplinar e abrangente, é também transformadora. Ela é uma ciência que reconhece e engloba o papel da co-construção, da importância da multissetorialidade e da busca por soluções participativas e transparentes, incluindo a ciência e o conhecimento tradicional. Consequentemente, fortalece e amplia o significado de ciência, com suas etapas, rigor e avaliaçōes como pilares do método científico, ao indicar a necessidade de engajamento de toda a sociedade, com vozes, mãos e mentes envolvidas desde a concepção até a entrega dos resultados, representando diferentes visões.

Certamente, a promoção de uma ciência interdisciplinar e transformadora é um processo que amplia os potenciais conflitos e as divergências entre múltiplos setores. Porém, é no entendimento dessas diferenças que está o potencial de inovação, transformação e aprendizados que precisamos para o desenvolvimento sustentável. A ciência deve visar a construção conjunta de soluções, reconhecendo a diversidade desde o início e trabalhando pela busca do bem comum. Desta forma, a ciência se aproxima da sociedade através da inclusão e do diálogo em todas as etapas, e não apenas após os resultados serem publicados. Esse movimento global convida cada país a trabalhar localmente para que as ações de sustentabilidade sejam na prática efetivadas, tenham suas condicionantes locais abrangidas e coloquem o oceano como exemplo de mudança.

DO LOCAL AO GLOBAL: AS CARACTERÍSTICAS DO BRASIL Além da produção científica englobando ciência oceânica [5, 6], o Brasil tem características que o colocam em destaque no contexto da Década do Oceano. Por um lado, um país de tamanho continental, com mais de $8.000 \mathrm{~km}$ de costa que abrange uma diversidade de ambientes terrestres, costeiros, marinhos e ilhas oceânicas, com características tropicais e subtropicais, e uma enorme riqueza sóciocultural-ambiental [3]. Por outro lado, somos um país que ainda carece de desenvolvimento tecnológico, com ampla desigualdade socioeconômica, com limitações e perdas nas regulamentações ambientais já conquistadas, com baixa cobertura de saneamento e com inúmeras fontes de poluição ao longo da costa, as quais geram múltiplos impactos - desde o uso direto, até os exemplos recentes de derramamentos de óleo ou rejeitos minerais. Assim, o Brasil pode ser atualmente traduzido como um país rico por natureza, biodiversidade e manifestaçôes culturais e, infelizmente, igualmente diverso em montante de impactos. Além disso, um país com alto potencial na ciência, com a garra de um povo e com a diversidade sócio-econômico-cultural-ambiental diretamente relacionada à Agenda 2030 e à Década do Oceano, que se mostra pronto para fortalecer o trabalho em conjunto em prol do desenvolvimento sustentável.

É nesse cenário que o Brasil tem sido pioneiro em diferentes açōes para a Década do Oceano. Além do escritório da Representação da Organização das Naçôes Unidas para a Educação, a Ciência e a Cultura (Unesco) no Brasil, temos a representação formal do Brasil na Comissão Oceanográfica Intergovernamental (COI) da Unesco pelo Ministério de Ciência, Tecnologia e Inovação (MCTI) e pela Marinha do Brasil. Na prática, o Brasil esteve atuante desde o início da fase preparatória da Década (2018-2020) com essas representações e com diferentes participações, açōes e eventos de setores acadêmicos e da sociedade civil organizada diretamente relacionados à Década, como o evento Conexão Oceano [9] e o lançamento da Cultura Oceânica no país [10]. Em 2020, duas ações se destacaram pela institucionalização da Década do Oceano pelo MCTI: a criação do Comitê Nacional de Assessoramento para a Década do Oceano e o lançamento da série de eventos O Brasil na Década do Oceano, que promoveu oficinas em todas as regiōes do país [11].

Em ambos os casos, as características essenciais do movimento global da Década do Oceano se fizeram presentes em sua estrutura nacional: grupos multissetoriais, buscando a equidade de gênero, etária e que reconhecem, respeitam e promovem a interdisciplinaridade e o alinhamento à Agenda 2030. A série de eventos O Brasil na Década do Oceano teve a sua concepção durante o Workshop Regional do Atlântico Sul [12,13] onde a COI Unesco promoveu a discussão entre países do Atlântico Sul para o planejamento para a Década do Oceano. Naquele momento, já se indicava que cada país deveria construir o seu planejamento nacional, um desafio e tanto para a maioria das naçōes. A proposta brasileira assumiu a necessidade de reconhecer a diversidade subnacional desse país de tamanho continental como ponto de partida. Assim, a partir da visão sobre o que as regiōes brasileiras possuem em comum e das potenciais diversidades entre elas, a proposta de elaborar o Plano Nacional ligando as características locais de cada região foi co-construída, considerando as vozes dos diferentes setores da sociedade, às demandas globais da Década do Oceano.

\section{A CO-CONSTRUÇÃO COM MÚLTIPLOS SETORES DA SOCIEDADE No}

Brasil, as características fundamentais da ciência oceânica transformadora proposta para a Década do Oceano foram assumidas desde o início. A co-construção entre múltiplos setores da sociedade esteve presente na concepção e planejamento das oficinas subnacionais, envolvendo setores governamentais (MCTI e Marinha do Brasil), intergovernamental (Unesco), academia (Universidade Federal de São Paulo - Unifesp) e sociedade civil (Rede ODS Brasil e Fundação Grupo Boticário), contando com a colaboração da juventude do setor empresarial (IMar Jr - empresa júnior de estudantes do Instituto do Mar da Unifesp) para sua execução. 
O processo participativo foi a linha central desse movimento. A inscrição dos participantes para as oficinas foi aberta a toda sociedade e se deu de forma voluntária, a partir de ampla mobilização nas redes sociais. A seleção de participantes se fez necessária nas oficinas realizadas nas regiōes Nordeste e Sudeste, onde o número de inscritos superou o esperado para as oficinas (em torno de 140 participantes). Nestes casos, os setores da sociedade com menor representatividade entre os inscritos foram priorizados, assim como a diversidade geracional, de gênero e geográfica, características essenciais da ciência transformadora (figura 1). Ao todo, foram 476 participantes, de 104 municípios de 20 unidades da federação (19 estados e o Distrito Federal). O setor acadêmico concentrou a maioria dos participantes (54\%), o que seria esperado por ser uma ação sobre a ciência, sendo os demais representantes dos setores governamental, empresarial, sociedade civil organizada e participantes individuais, demonstrando interesse diverso e o potencial da co-construção científica. Um destaque foi a participação consistentemente maior (aproximadamente 60\%) de mulheres em todas as regiôes, garantindo e reforçando a equidade de gênero para a Década do Oceano [7].

De forma geral, as oficinas foram desenhadas para incluir a perspectiva dos diferentes setores da sociedade em relação aos sete resultados esperados para a Década do Oceano (em 2030 queremos: um oceano limpo; um oceano saudável e resiliente; um oceano previsível; um oceano seguro; um oceano produtivo e sustentável; um oceano transparente e acessível; um oceano que inspira e engaja; [1, 12]). Assim, os trabalhos aconteceram em três etapas: i) "o oceano que temos" em 2020; ii) a "ciência que precisamos" durante a década (quais questôes científicas? Que tipo de capacitaçôes são necessárias? Qual a demanda de infraestrutura? Quais bases de dados devem ser geradas e como promover acessibilidade às informaçōes e conhecimentos? Como comunicar para todos e engajar a sociedade?) para atingir; iii) "o oceano que queremos" em 2030. Nesse contexto, era importante que as múltiplas visóes representassem a realidade regional, com suas características, potencialidades e desafios, além de trazer a discussão aos Objetivos do Desenvolvimento Sustentável, mantendo o foco do planejamento de futuro através da ciência transformadora.

Para promover a co-construção e dar destaques às regionalidades, as oficinas foram realizadas com metodologias ativas de mediação de conflitos e busca de consenso. Essas metodologias são aplicadas em todo o mundo promovendo diálogo para inclusão e aceitação de múltiplas perspectivas, vivências, expectativas e conhecimentos em prol de objetivos comuns. Mais recentemente, as abordagens de mediação de conflitos têm sido tópico de estudo para desenvolvimento de políticas públicas participativas cientificamente embasadas na realidade brasileira [14]. Essas propostas promovem um debate horizontal, assumindo como preceito fundamental que todos os grupos da sociedade têm a mesma relevância no processo de construção. Dependendo do tópico em discussão, participantes de determinado setor podem ter maior apropriação prática ou teórica, seja por conhecimento tradicional, científico ou de gestão, mas isso não os coloca em prioridade frente aos demais. A mediação é um componente do processo, evitando que a habilidade de oratória, o tom da voz ou a timidez exerçam assimetria entre participantes e levem a resultados restritivos.

Promover a inclusão, o sentimento de pertencimento, a empatia, o diálogo e garantir o espaço de voz a todos os participantes são características - e muitas vezes desafios - na facilitação de processos colaborativos. A comunicação é ferramenta fundamental para a co-construção, sendo que, muitas vezes, diferentes setores da sociedade possuem estilos diferentes de se comunicar e agir, relacionados ao pragmatismo, aos termos utilizados e a forma de comunicação. Da mesma forma, nossas características individuais trazem diversidade ao grupo, que através das ferramentas de coconstrução são transformadas em riqueza e não em divergência. Assim, nesse processo, é preciso identificar as diferenças de forma, conceitos e termos que podem ser mais acessíveis e comuns na comunicação para um determinado setor, mas não para os demais. Apesar da complexidade na co-construção multissetorial, a essência da condução passa a reconhecer nas diferenças e na assimetria de conhecimentos e experiências a oportunidade de argumentar e de construir consenso e inclusividade com um resultado que esteja de acordo com as várias visōes.

É fato que consenso é desejável, mas nem sempre existe. Alcançar o reconhecimento da multiplicidade de visōes é uma forma, importante e inclusiva, de promover consenso. Para tal, se não alcançar o consenso, se vale da democracia e acordo de todas as partes para manter o resultado indicado pela maioria. $\mathrm{Na}$ experiência das oficinas O Brasil na Década do Oceano, temos a felicidade de dizer que a promoção do debate, a escuta ativa e empática, a exposição das diferenças de opiniōes, a argumentação respeitosa, embasada e, quando necessária, mediada para superar conflitos, foi suficiente para chegar a produtos consensuais por todos os participantes, na grande maioria dos casos.

\section{O BRASIL NA DÉCADA DO OCEANO: EXPERIÊNCIAS E APRENDIZADOS}

A experiência brasileira na co-construção de ideias para a Década do Oceano pelas regiōes do país trouxe avanços e aprendizados. Como qualquer processo participativo, apresentou desafios e teve limitações, mas mostrou caminhos a serem seguidos. Do ponto de vista operacional, as oficinas que seriam inicialmente presenciais foram adaptadas para o mundo on-line no cenário da pandemia da covid-19. Na prática, as oficinas online permitiram que uma maior diversidade geográfica pudesse participar, dado que muitos participantes não teriam recursos para deslocamento e hospedagem em um evento presencial. Por outro lado, trouxe obstáculos para grupos com limitação de acesso à internet, em especial comunidades tradicionais. Entre avanços e desafios, algumas soluções foram desenvolvidas pelos próprios participantes: houve aqueles 
Figura 1 - Total de participantes (476) das oficinas subnacionais 0 Brasil na Década do Oceano e sua distribuição por oficina, gênero, setor da sociedade, idade e cor/raça/etnia

\section{6 participantes}
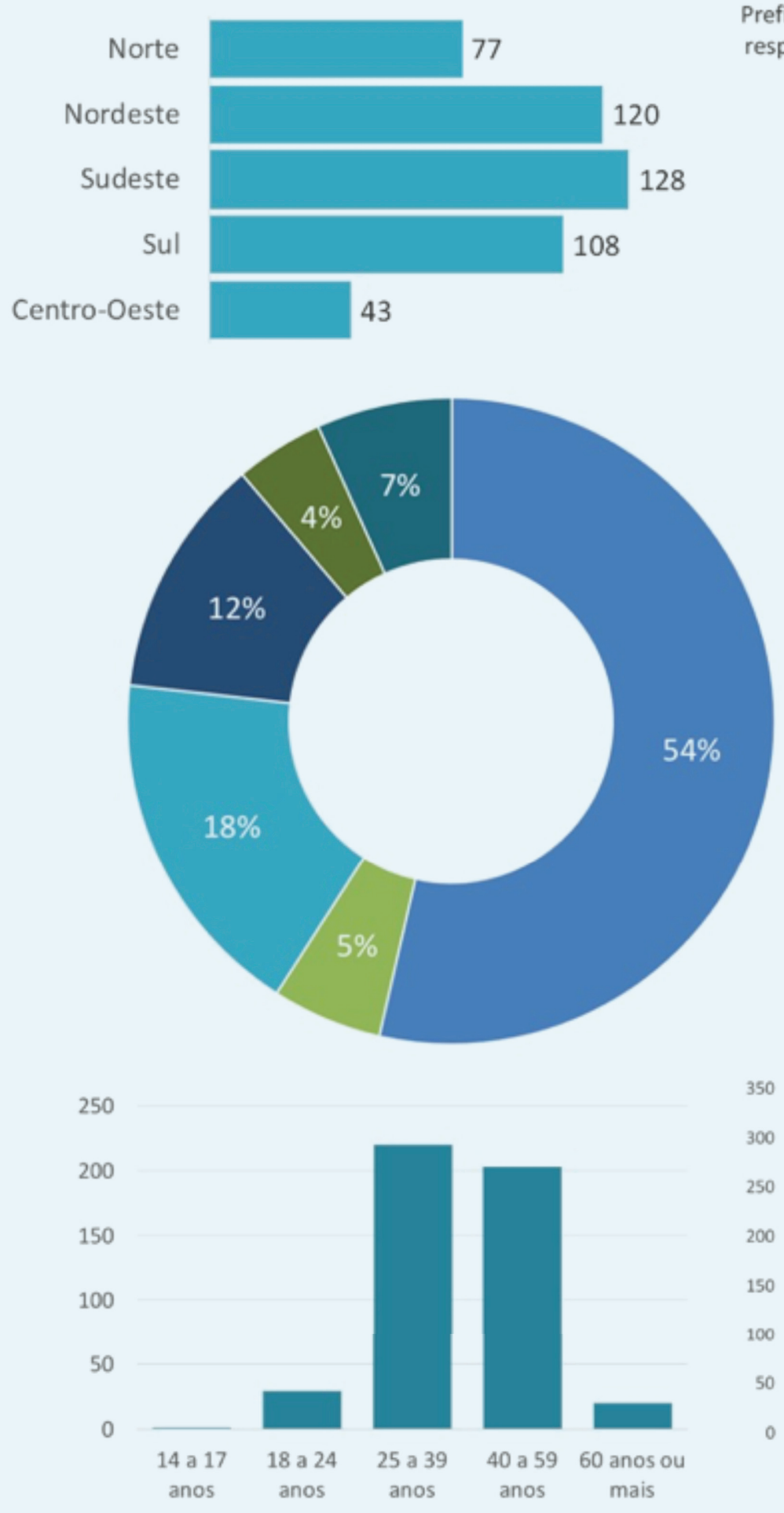

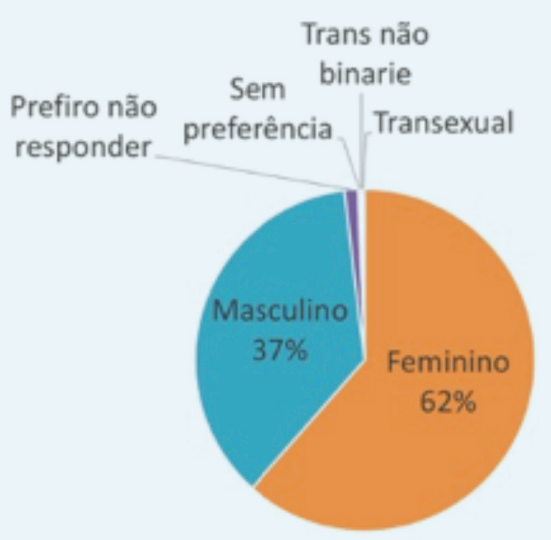

- Academia / Ensino Superior

- Empresarial / Empresas

" Governo

- Organização Não Governamental / Privado Sem Fins Lucrativos

- Participante sem afiliação

- Sociedade Civil

350

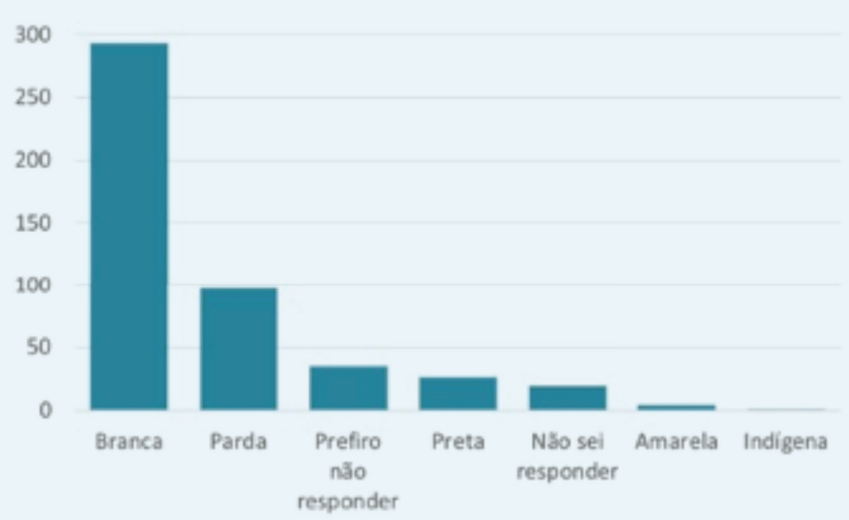


em diferentes regiōes que diariamente, ou em momentos anteriores e posteriores às oficinas, estabeleceram o contato com as comunidades mais próximas e atuaram como uma representação daquelas vozes. Além disso, a conciliação entre diversas formas de trabalho (síncrono e assíncrono) possibilitaram a inclusão das ideias e contribuiçôes, conciliadas à rotina dos participantes.

Em termos do conteúdo técnico produzido, os resultados das oficinas foram sintetizados em planos estratégicos no formato de relatório para cada região do país, os quais estão disponíveis na página oficial da Década do Oceano no Brasil para download [11], bem como as apresentações resumidas para cada região do país realizadas em formato de webinar [15]. Nestes produtos, algumas características regionais ressaltaram de forma bastante similar para os mais de 20 membros da equipe de facilitação e relatoria. Essa percepção se deu pois em cada oficina havia sete grupos de trabalho concomitantes, cada um trabalhando um dos sete resultados esperados para a Década do Oceano. Assim, como os grupos trabalhavam independentemente, as percepções similares dos mediadores e facilitadores entre grupos de uma mesma região nos indicaram características regionais do processo de co-construção. É importante destacar que elas não foram exclusivas de uma região, mas apenas visões que mais se destacaram em determinada região na visão dos autores deste trabalho.

Em termos de similaridade entre regiōes, as características de conflitos preestabelecidos entre grupos, limitação de recursos financeiros, dados existentes, mas não amplamente disponibilizados, a necessidade de fortalecimento de açôes de comunicação, educação e da criação de um órgão nacional para a ciência oceânica estiveram sempre presentes. Ainda, a proatividade, o comprometimento, o entusiasmo em se engajar na Década, junto ao reconhecimento da importância da valorização das comunidades e conhecimento tradicional nesse processo foram referenciados em todas as regiões.

Em relação ao processo de co-construção, o início foi precedido de uma percepção de dúvida, estranhamento, questionamento ou insegurança sobre o processo participativo e de busca do consenso, os quais invariavelmente cederam lugar à confiança, entrega, comprometimento e reconhecimento do processo no decorrer das oficinas. Como mencionado anteriormente e enaltecendo aqui, a diversidade cultural do país, os estilos de comunicação e interação variaram entre indivíduos, instituições e até pelas características regionais. Porém, um consenso existiu: na avaliação final das oficinas, todos reconheceram o processo, a mediação e a oportunidade de que sua voz fosse igualmente ouvida em relação aos demais participantes.

Em termos de peculiaridades, a região Norte se destacou pela visão regional, com a inclusão das comunidades tradicionais e falas que destacam a paixão e os sentimentos pelas características locais. Na região Nordeste, as questões sociais e de infraestrutura emergiram com maior intensidade, e as regiōes Sudeste e Sul depo- sitaram maior atenção em discussões de aspectos técnicos e solução para os desafios de um desenvolvimento sustentável. Enquanto as discussões sobre aspectos científicos da interação entre múltiplos fatores e da interação do regional ao nacional e global estiveram mais presentes na região Sudeste, na região Sul a operacionalização e a contribuição regional foram bastante destacadas. Já na regiāo Centro-Oeste, os aspectos de governança ressaltaram frente às diferentes temáticas, trazendo a importância da gestão participativa para sustentabilidade. Como mencionado, em nenhum caso essas visões foram exclusivas em uma determinada região, mas sim as de maior destaque percebidas por toda a equipe executora, independente do grupo de trabalho.

Além das características regionais, também foram observados perfis similares de participantes para um mesmo tema/resultado esperado da Década entre as diferentes regiões, fossem eles perfis mais técnicos, sociais, operacionais ou de engajamento. Certamente estas características estão relacionadas com o objetivo de cada um dos resultados esperados para a Década do Oceano e o como cada setor da sociedade e perfil de indivíduo se conecta com aquele objetivo.

Considerando todo o processo, um aprendizado se destaca e diz respeito ao potencial brasileiro no processo de tomada de decisão cientificamente embasada. Essas oficinas demonstram como o governo federal pode inovar na construção de políticas públicas de gestão da ciência com abordagens de formulação participativas. Essa foi uma experiência com ampla representação local e regional se comparado ao modo usual de formulação de programas governamentais e instrumentos similares anteriores. Desde o início o MCTI e parceiros internalizaram os valores do conhecimento científico co-construído como uma ferramenta transformativa ao longo de todo o seu processo e mostrou o esforço de engajamento da sociedade no planejamento de futuro, desde a concepção até a entrega dos resultados. Esse processo, com seus aprendizados e desafios, poderá auxiliar para que muitos processos similares sejam realizados nas esferas governamentais e na produção de políticas públicas que considerem os conceitos de ciência transformadora.

Foi perfeito? Absolutamente não, porém, trouxe aprendizados, interaçôes e oportunidades que nos permitem fortalecer e expandir processos participativos e de co-construção no qual as vozes se sintam reconhecidas e ouvidas. Estamos certos de que os participantes e organização deram o melhor de si e produziram documentos valiosos para a construção de um futuro sustentável a partir do oceano já no início da Década. Avanços, ampliações e ajustes fazem parte de um processo dinâmico. Porém, foi frequentemente registrado na avaliação dos participantes o ineditismo do processo e o desejo de que ele continue, se expanda e seja institucionalizado. Desta forma, a ciência oceânica transformativa tem um grande potencial e um importante papel no desenvolvimento sustentável brasileiro. 
E EU COM ISSO? A ciência transformadora é participativa, inclusiva, colaborativa, transparente, co-construída e co-desenvolvida, engloba diferentes setores da sociedade, a diversidade geracional, de gênero, geográfica e cultural, o conhecimento científico e o tradicional. Logo, ela é dinâmica, inovadora e desafiadora. A ciência transformadora abre a oportunidade de participação, da contribuição e para que todas as vozes façam a diferença no planejamento e implementação do futuro. Esse dinamismo tem por característica o fato de que nem sempre o próximo passo está pronto, pelo contrário, ele emerge naturalmente do processo. As soluçōes devem ser elaboradas em conjunto ao longo da co-construção e adaptadas às diferentes realidades. Por isso, apesar da existência prevista, nem sempre todos os passos e respostas estão definidos desde o início.

As pessoas usualmente esperam uma resposta pronta para os seus anseios sobre a Década do Oceano. Nesse caso, respostas prontas seriam um retorno ao modo usual de fazer ciência e políticas públicas, onde as respostas e formatos estão pré-definidos. Em processos de ciência transformadora é necessário reconhecer que não existem respostas prontas. Precisamos conter nossa ansiedade e exercitar nossa habilidade de trabalho em grupo para que as respostas e processos sejam efetivamente co-construídos e co-entregues. Não ter caminhos prontos não significa falta de organização ou planejamento. Mostra simplesmente que os grupos na gestão e organização estão tentando incluir todas as visões possíveis e buscando consenso para propor a melhor solução e, consequentemente, engajamento.

Processos de co-construção são complexos e por isso demandam respostas e ações igualmente complexas. Respostas e ações complexas, por sua vez, demandam diálogos, planejamento, organização e respeito ao tempo de todos os setores no diálogo e busca de consenso. Por isso, nem sempre a resposta mais rápida é a mais adequada. Nenhum processo inovador se faz com o uso inquestionável dos métodos até hoje aplicados. Precisamos estar abertos ao novo. Nenhum processo inovador se faz sem reconhecer todo o avanço, benefícios e aprendizados que os caminhos anteriores trouxeram. Não é sobre recomeçar do zero, mas sim sobre adaptar, incluir e aplicar novas formas, mais diversas, participativas e transparentes, a partir das valiosas experiências que nos trouxeram até aqui. Esta é a oportunidade que a Década do Oceano nos traz.

Qual o seu papel? A Década depende de cada um de nós. Se as metas e objetivos do oceano que queremos acontecerão na prática, dependerá do quanto cada um de nós, como indivíduo e instituição, está comprometido a compartilhar suas melhores experiências, aberto para aprender com a vivência do outro, preparado para promover mudanças - internas, institucionais e de políticas públicas - e nos conduzir para um futuro sustentável. Não existem regras fixas e caminhos totalmente conhecidos, mas existe espaço em que podemos aprender e construir juntos. A decisão de como, quando e porque participar, só depende de você. Não é necessariamente sobre apontar o que "o outro" deve fazer ou melhorar, mas também reconhecer qual é o "meu" papel e "a minha mudança". No mundo atual, a expressão "precisamos sair da caixinha e da zona de conforto" reflete esse processo que nem sempre é fácil, costuma trazer insegurança e questionamentos, e onde o passo seguinte depende de cada um de nós. Se você está disposto a aceitar o convite que a Década da Ciência Oceânica para o Desenvolvimento Sustentável traz sobre o olhar para a sustentabilidade a partir do oceano, a ser construída com as mãos de todos e para todos, o Comitê Nacional e os Grupos de Apoio a Mobilização [11], que surgiram organicamente em cada uma das regiōes, podem ajudá-lo(a,e) a encontrar o seu espaço e contribuir para a ciência que precisamos para o futuro que queremos. Seja bem vindo(a,e)!

Ronaldo A. Christofoletti, Andrezza J. Gozzo, Fernando R. Martins, Tatiana M. Mazzo, Barbara L. Ignacio, Marcelo V. Kitahara, Melissa V. Rodrigues e Leonardo Q. Yokoyama são docentes do Instituto do Mar da Universidade Federal de São Paulo (IMar/Unifesp), membros do Programa Maré de Ciência e responsáveis pela mediação das oficinas subnacionais "O Brasil na Década do Oceano". Contato: christofoletti@ unifesp.br.

Ana Carolina de A. Mazzuco e Paula Kasten são pós-doutorandas financiadas pelo CNPq, respectivamente, na Universidade Federal do Espirito Santo (Ufes) e IMarl Unifesp; colaboradoras do Programa Maré de Ciência e responsáveis pela mediação das oficinas subnacionais "O Brasil na Década do Oceano".

Amanda V. Aguiar, Bruno H. Basso, Carolina F. Faria, Crhisângela G. R. Ferreira, Felicia C. Gasparini, Henrique Morgan, Henrique V. Dantas, Henry M. Raphael, Lucas R. Ozores, Luisa F. Medeiros, Mariana C. Lazaretti e Matheus T. Mathias são graduando(a)s do bacharelado interdisciplinar em ciência e tecnologia do mar da Unifesp e membro(a)s da IMar Jr, empresa júnior responsável pela relatoria das oficinas subnacionais "O Brasil na Década do Oceano".

Aline C. de Sousa, Juliana S. Pires, Kananda M. Vieira, Mariane S. Guarachi e Murilo F. Carvente são graduando(a) sem engenharia do petróleo e recursos renováveis, graduado(as) no bacharelado interdisciplinar em ciência e tecnologia do mar Unifespe membro(a)s da IMar Jr, empresa júnior responsável pela relatoria das oficinas subnacionais "O Brasil na Década do Oceano".

Ketellyn S. dos Santos, Sabrina C. da S. Nascimento e Stheffany de Oliveira Santos são graduandas em engenharia ambiental, graduadas no bacharelado interdisciplinar em ciência e tecnologia do mar Unifesp e membras da IMar Jr, empresa júnior responsável pela relatoria das oficinas subnacionais "O Brasil na Década do Oceano".

\section{NOTAS E REFERÊNCIAS}

1. Intergovernmental Oceanographic Commission (IOC) of Unesco. Implementation Plan - United Nations Decade of Ocean Science for Sustainable Development 2021 - 2030. Version 2.0. 2020. Disponível em 〈https://oceanexpert.org/document/27347〉. Acesso em 23 fev 2021

2. PNUD. Agenda 2030 para o Desenvolvimento Sustentável. Disponível em 〈http://www.agenda2030.com.br/sobre/〉. Acesso em 23 fev 2021

3. Ver artigo "Conexão oceano, ciência e sociedade", de Capretz e Madalosso, nesta edição da Ciência \& Cultura.

4. Christofoletti, R. A.; Lindoso, V. G.; Nunes, M. "Sem oceanos, um futuro impossível". Ciência Hoje. 2019. Disponível em <https://cienciahoje.org.br/artigo/sem-oceanos-um-futuro-impossivel/>. Acesso em 23 fev 2021. 
5. Ver o artigo "A ciência oceânica no Brasil e desafios transversais para a produção do conhecimento", de Pinho e colaboradores, nesta edição da Ciência \& Cultura.

6. Turra, A.; R. de Pinho \& J. B. de Andrade. "Cooperação internacional do Brasil em ciência oceânica". 2021. Ciência \& Cultura neste volume

7. Ver artigo "A perspectiva de futuro e o potencial de transformação social e econômica a partir da ciência oceânica", de del Favero e de Andrade, nesta edição da Ciência \& Cultura. a. 2021.

8. Ver artigo "Maré de informação para promover a cultura oceânica", de Germana Barata, nesta edição da Ciência \& Cultura. 2021.

9. Conexão Oceano -10 evento voltado para Comunicação sobre a Década do Oceano no Brasil, organizado pela Fundação Grupo Boticário de Proteção à Natureza, Unesco no Brasil, Comissão Oceanográfica Intergovernamental (COI) da Unesco e Museu do Amanhã. 2019. Disponível em <http://www.fundacaogrupoboticario.org.br/pt/Biblioteca/Produto\%20Conex\%C3\%A30\%200ceano.pdf〉. Acesso em 23 fev 2021.

10. Alisson, E. “Unesco lança versão em português de kit pedagógico sobre oceanos". Agência Fapesp. 2020. <https://agencia.fapesp.br/ unesco-lanca-versao-em-portugues-de-kit-pedagogico-sobre-oceanos/33251/>. Acesso em 23 fev 2021.

11. Página oficial da Década da Ciência Oceânica no Brasil. MCTI. 〈http:// decada.ciencianomar.mctic.gov.br/>. Acesso em 23 fev 2021.

12. Intergovernmental Oceanographic Commission (IOC) of Unesco. Summary Report of the Regional Planning Workshop for the South Atlantic. Rio de Janeiro 25-27/11/2019. Disponível em <https://oceandecade.org/resource/95/-Summary-Report--South-Atlantic-Regional-Workshop-25-27-November-2019-in-support-of-the-UN-Decade-of-Ocean-Science-for-Sustainable-Development-2021-2030〉. Acesso em 23 fev 2021.

13. I Webinar Nacional “Onde estamos?" da série de eventos O Brasil na Década do Oceano com a apresentação dos resultados do Relatório do Workshop de Planejamento para o Atlântico Sul em português. Disponível em <https://www.youtube.com/watch?v=IUIUng1IQhs\&feature=emb_logo . Acesso em 23 fev 2021.

14. A metodologia aplicada nas oficinas subnacionais O Brasil na Década do Oceano foi adaptada para a realidade brasileira no projeto "Coastal biodiversity and public policies: methodologies and actions to integrate stakeholders" com financiamento do Programa de Políticas Públicas da Fapesp (2017/50220-8) e do British Council. Disponível em <https://bv.fapesp.br/pt/auxilios/99262/coastal-biodiversity-and-public-policies-methodologies-and-actions-to-integrate-stakeholders/>. Acesso em 23 fev 2021.

15. Canal Youtube oficial da Década da Ciência Oceânica no Brasil com as apresentações dos resultados de cada oficina subnacional. Disponível em <https://www.youtube.com/c/D\%C3\%A9cadadaCi\%C3\%AAnciaOce\%C3\%A2nicaBrasil/featured〉. Acesso em 23 fev 2021. 